\title{
O ENSINOIAPRENDIZADO DO BIM NO CURSO DE ENGENHARIA CIVIL DA UFJF 1
}

\author{
BIM TEACHING/LEARNING IN THE COURSE OF CIVIL ENGINEERING IN \\ UFJF
}

\author{
Mauricio Leonardo Aguilar-Molina \\ Universidade Federal de Juiz de Fora (UFJF) \\ mauricio.aguilar@engenharia.ufif.br \\ Waldyr Azevedo Junior \\ Universidade Federal de Juiz de Fora (UFJF) \\ waldyr@engenharia.ufjf.br
}

\begin{abstract}
Resumo
O setor da Arquitetura, Engenharia e Construção vem mostrando significativa preocupação pela qualidade em função da exigência do mercado de melhores patamares de desempenho nos novos projetos. O BIM vem crescendo significativamente no Brasil, trazendo uma contribuição na solução dos problemas do setor. Aos poucos, o mercado começa a exigir soluções nestes moldes, colocando uma demanda significativa na formação de profissionais do setor. Este trabalho apresenta a experiência na introdução do BIM no curso de Engenharia Civil da Universidade Federal de Juiz de Fora (UFJF). À luz dos resultados obtidos, percebe-se - neste caso que a grade curricular do curso constitui uma séria limitação, pois não oferece espaço ao aprendizado do projeto nem mecanismos que possibilitem aos alunos vivenciar a complexidade da interação entre diferentes especialidades, com perda da necessária visão sistêmica subjacente ao BIM. Esta percepção está de acordo com alguns relatos de experiências nacionais e internacionais, os quais coincidem na necessidade de identificar as competências que precisam ser desenvolvidas na formação dos profissionais para terem proficiência no campo do BIM. O trabalho termina com algumas considerações sobre o currículo do curso, destacando-se o papel da Expressão Gráfica e a valorização de competências de modelagem e colaboração em projeto.
\end{abstract}

Palavras-chave: BIM. Modelagem. Projeto de Engenharia. Competências. Educação.

\begin{abstract}
The industry of Architecture, Engineering and Construction shows significant preoccupation with quality standards due to market requirements for higher levels of performance in new projects. BIM is growing significantly in Brazil, bringing a contribution to solve industry problems. Gradually, the market demands solutions in this way, placing significant demand in the formation of professionals. This paper presents the experience in introducing BIM in the civil engineering course in UFJF. According with the results obtained, it can be seen that the course curriculum is a serious constraint, as it neither offers space for design learning nor mechanisms that allow students to experience the complexity of the interaction among the different specialties, with the loss of the necessary systemic view, which is underlying to BIM. This perception agrees with some national and international experiences, which coincide on the need to identify the skills that should be developed in the formation of professionals for being proficient in BIM. Finally, some considerations on the course curriculum are presented, highlighting the role of graphic expression and the need for modeling skills and collaboration in design.
\end{abstract}

Keywords: BIM. Modeling. Engineering Design. Competencies. Education.

\footnotetext{
1 AGUILAR, M.; AZEVEDO, W. O Ensino/Aprendizado do BIM no curso de Engenharia Civil da UFJF. In: ENCONTRO BRASILEIRO DE TECNOLOGIA DE INFORMAÇÃO E COMUNICAÇÃO NA CONSTRUÇÃO, 7. 2015, Recife. Anais... Porto Alegre: ANTAC, 2015.
} 


\section{INTRODUÇÃO}

As novas edificações têm uma complexidade crescente, relacionada com novas demandas, originadas numa consciência mais ampla em torno dos impactos de uma indústria tradicionalmente agressora ao meio ambiente e com baixos níveis de produtividade.

Num cenário que exige melhores soluções e melhor aproveitamento dos recursos, a incorporação de novas tecnologias no ciclo de vida das edificações traz novos desafios para o projeto e a necessidade de conciliar uma grande quantidade de variáveis tradicionalmente negligenciadas no processo do ciclo de vida da edificação. Com a tendência crescente à industrialização dos processos construtivos, há a exigência de se resolver muitas situações ainda nas etapas do projeto preliminar, a fim de lidar com a grande variedade de componentes manufaturados hoje utilizados pelo setor, com a consequente exigência de compatibilidade entre eles.

O desenvolvimento de novas Tecnologias da Informação e da Comunicação (TICs) nas últimas décadas possibilitou uma melhoraria gradativa dos processos do setor da Arquitetura, Engenharia e Construção (AEC). A incorporação da tecnologia CAD significou um avanço fundamental das últimas décadas, pois, inicialmente, possibilitou a automatização de cálculos complexos, deixando os projetistas com mais espaço para tarefas de análise. O desenvolvimento de dispositivos de hardware para computação gráfica fez possível o desenho assistido por computador. A melhoria da capacidade dos dispositivos de hardware em termos de memória e processamento possibilitou alavancar, primeiramente, a modelagem geométrica e, numa etapa posterior, no final da década de 1980, a modelagem do produto (KALE; ARDITI, 2005), uma tecnologia precursora do BIM.

As novas TICs têm sido usadas para racionalizar, desenvolver processos e gerir dados da construção de edifícios, especialmente aqueles com maior complexidade formal-espacial. No entanto, a incorporação das novas TICs está ainda longe de ser uma realidade dentro das construtoras e incorporadoras brasileiras. Mas, ao que tudo indica, o crescimento do mercado deve estimular o setor a rever seus conceitos nessa área. Diante de margens de lucro cada vez mais reduzidas, a alternativa é investir em tecnologias e ferramentas para controlar e otimizar todos os processos que envolvem uma obra, reduzindo, desse modo, desperdícios de tempo e dinheiro.

A complexidade de alguns projetos contemporâneos requer novos procedimentos de gerenciamento de informações. Para administrar esses tipos de projetos tem expandido o uso das TICs, possibilitando controlar dados digitais dos projetos com geometria mais complexa, assim como programar a sequência de atividades relativas à construção.

O objetivo deste trabalho é fazer algumas considerações sobre a importância do BIM enquanto meio privilegiado tanto para a atividade projetual quanto para a integração de disciplinas num contexto de Engenharia Simultânea. São discutidos também os desafios da inserção do BIM no currículo do curso de Engenharia Civil da UFJF. Tendo constatado, pela experiência do curso, que reformas curriculares em profundidade são de difícil consenso, os autores destacam o papel da Expressão Gráfica enquanto espaço para avanço e valorização de competências de modelagem e colaboração em projeto.

\section{O QUE É BIM}

BIM é o acrônimo do conceito de Building Information Modeling, sendo traduzido para a língua portuguesa tanto como Modelo quanto Modelagem da Informação da Construção. $\mathrm{Na}$ ótica de modelo, o BIM consiste num conjunto de informações geradas e mantidas durante todo o ciclo de vida de uma obra, desde sua concepção, passando pela sua construção e implantação, até a fase de demolição ou requalificação para uso (EASTMAN et Al., 2011). 
O BIM possibilita o compartilhamento de informações e uma comunicação mais eficaz e interativa entre os diferentes stakeholders em cada fase do ciclo de vida da obra, oferecendo informações coerentes e confiáveis a todos os interessados.

O estado atual da arte das TICs possibilita o acesso ubíquo à informação do modelo por todos os interessados, pois a mesma é armazenada em bancos de dados acessíveis através da Internet e por meio de uma ampla variedade de dispositivos. Deste modo, as alterações num modelo podem ser processadas em tempo real e todos os interessados podem ter acesso à informação atualizada, eliminando a burocracia tradicional baseada na entrega de documentação em papel com controle de versões.

Com as ferramentas BIM, o resultado do projeto arquitetônico, baseado fortemente na representação em 3D da arquitetura, vai além da simples representação gráfica do projeto, fornecendo uma referência consistente para as diferentes disciplinas da engenharia e com impacto no processo de execução da obra projetada.

Desse modo, o BIM tem grande impacto na construção, pois possibilita a integração do projeto arquitetônico com os projetos das diferentes disciplinas da engenharia, fornecendo os elementos necessários para simular a sequência construtiva da obra e, ainda tornando possível a incorporação de considerações de sustentabilidade.

É habitual a associação do BIM com aplicativos de modelagem 3D específicos, o que pode levar a uma incompreensão do BIM, de modo que a forma como entendemos o BIM tem grande relevância, pois disso dependerá a avaliação apropriada dos seus benefícios.

Existem, na atualidade, diferentes definições para o conceito de BIM, dependendo da percepção dos seus autores. Isso tem efeito nas decisões tomadas quanto à forma de implementação. Nesse sentido, de acordo com BARISON (2015), se o BIM for entendido apenas como uma nova ferramenta tecnológica ou metodológica, o impacto dessa visão no âmbito educacional poderá ser limitado num currículo de curso de Engenharia Civil.

A segmentação do ciclo de vida da obra leva a um distanciamento entre os diferentes atores do processo, os quais, em seus espaços disciplinares, desenvolvem linguagens particulares, nem sempre compreensíveis entre si. Como a obra constitui um objeto só, se os atores usarem linguagens diferentes, essa diferença pode acabar escondendo a unidade da obra projetada. Nesse sentido, o BIM, como um conjunto de modelos interoperáveis, permite a remissão dos atores particulares à unidade da obra. O BIM possibilita a compatibilidade entre modelos ao remeter à unidade original da obra, com um trabalho mais coordenado e orgânico.

Quando adotado com a consciência de suas potencialidades, o BIM possibilita a integração do processo de projeto e construção, o qual resulta em obras de melhor qualidade, a custos mais baixos e prazo de execução do projeto reduzida (SACKS et Al., 2009).

Portanto, considerando que o BIM envolve uma mudança de paradigma na indústria da Construção Civil, a formação de profissionais com uma adequada compreensão dos seus conceitos constitui um desafio interessante para a academia e sua superação será fundamental para possibilitar a adoção deste novo paradigma pelo mercado nacional.

\section{PROJETO NA ENGENHARIA CIVIL}

A formação dos profissionais da Engenharia Civil no Brasil está definida através da Resolução CNE/CES de 11 de março de 2002, a qual Institui Diretrizes Curriculares Nacionais do Curso de Graduação em Engenharia no país:

Art. $3^{\circ} \mathrm{O}$ Curso de Graduação em Engenharia tem como perfil do formando egresso/profissional o engenheiro, com formação generalista, humanista, crítica e reflexiva, capacitado a absorver e desenvolver novas tecnologias, 
estimulando a sua atuação crítica e criativa na identificação e resolução de problemas, considerando seus aspectos políticos, econômicos, sociais, ambientais e culturais, com visão ética e humanística, em atendimento às demandas da sociedade. (CNE, 2012)

Tal diretriz estabelece de modo geral algumas características do perfil profissional, deixando para as instituições a responsabilidade pela definição dos currículos que permitirão formar tais profissionais. Em alguns casos, no entanto, se observa que a atualização dos currículos não é feita com a frequência necessária. Neste sentido, na opinião dos autores, a definição de um currículo deveria estabelecer, como condição mínima de validade, mecanismos para sua atualização periódica, seja de objetivos estratégicos (longo prazo, por exemplo, 5 anos), táticos (médio prazo, por exemplo, 2 anos) e operacionais (curto prazo, por exemplo, a cada semestre letivo), seja de recursos didáticos. Desse modo, seria possível manter sem sobressaltos sua atualidade, o que não é comum observar nas condições atuais, onde alguns currículos - particularmente o da UFJF - não dão conta devidamente das mudanças no âmbito do mercado profissional, como parece ser o caso da adoção do BIM. De fato, instâncias governamentais já começam a exigir projetos segundo o paradigma BIM (SANTOS, 2014), o qual traz uma demanda concreta de atualização para o currículo dos cursos de engenharia civil.

Numa perspectiva projetual, a formação dos engenheiros civis da UFJF tem como grande limitação um aprendizado pautado por esquemas - metodologias e técnicas - baseados na repetição de práticas já consagradas, localizadas em áreas disciplinares específicas, com pouco espaço para a criatividade, inovação e visão holística, conforme preconizado pela referida diretriz (AGUILAR; AZEVEDO, 2014).

Por outro lado, a recente Resolução 51/2013 do Conselho de Arquitetura e Urbanismo do Brasil (CAU, 2013), que define o projeto em diferentes âmbitos como atribuição exclusiva de Arquitetos e Urbanistas, torna ambígua a definição das competências e atribuições profissionais de Engenheiros Civis, de acordo com a Resolução 1048/2013 do CONFEA (2013).

Junta-se a isso a falta de uma definição atualizada do perfil dos engenheiros civis formados pela UFJF, o que traz como consequência que as competências inerentes e subjacentes à visão integradora do projetar não estejam devidamente caracterizadas no currículo do curso, conforme já constataram Lana e Andery (2002). Ainda em relação com o currículo do curso de Engenharia Civil da UFJF, também são verificadas as constatações de Lana e Andery quanto ao desequilíbrio na importância das disciplinas das diferentes áreas do curso no currículo, com predominância das áreas de Transporte e Geotécnica e Estruturas. De fato, numa análise do atual projeto pedagógico do curso de Engenharia Civil da UFJF, cujo texto foi aprovado pelo Colegiado do Curso de Engenharia Civil em 2010, mas ainda não foi publicado oficialmente, a distribuição de disciplinas por área tem os seguintes pesos: Transportes e Geotécnica - 30\%, Estruturas - 25\%, Hidráulica e Saneamento - 20\%, Construção Civil - 14\% e Mecânica Aplicada e Computacional -12\%.

Os autores julgam da maior importância o resgate do aspecto projetual na formação dos futuros engenheiros civis, tanto em seu aspecto criativo quanto na visão sistêmica, instrumentalizada pela Engenharia Simultânea, conforme caracterizada por Fabrício (2002), e que pode ser operacionalizada pelo BIM.

A adoção do BIM como novo paradigma pressupõe a derrubada das fronteiras disciplinares através do conceito de Engenharia Simultânea, o qual considera todos os aspectos do ciclo de vida da edificação já na fase conceitual. Desse modo, o BIM é um meio privilegiado para a realização da Engenharia Simultânea. No entanto, com um aprendizado segmentado, há poucas chances de se viabilizar esta visão integrada preconizada pelas diretrizes do Conselho Nacional de Educação. 


\section{O PAPEL DA EXPRESSÃO GRÁFICA}

Os autores clássicos French e Vierck justificam a razão pela qual o Desenho Técnico deve ser ensinado no início de um curso de engenharia, considerando que um desenho é mais do que a simples representação pictórica de um objeto. É uma linguagem gráfica completa, por meio da qual é possível descrever minuciosamente cada operação e guardar um registro completo da peça, para reprodução ou reparos (FRENCH; VIERCK, 2005).

O Desenho Técnico constitui a base de qualquer projeto de engenharia e, de modo similar à matemática, pode ser considerado como a matéria mais importante. French e Vierck prescrevem que a Expressão Gráfica, como base da competência projetual, deve ser ensinada nos primeiros períodos, pois seu ferramental será utilizado ao longo da formação do engenheiro e, depois, no resto da vida do profissional. Eles destacam ainda a importância do desenho como linguagem formal e a necessidade de que todo engenheiro seja capaz de desenvolver a precisão através da utilização de instrumentos - sejam tradicionais tais como lápis, réguas e compassos, bem como computadores e impressoras de alta qualidade - além da destreza manual para adquirir, por uma observação adequada, o perfeito domínio da forma e da proporção.

$\mathrm{Na}$ UFJF, o aprendizado da Expressão Gráfica acontece nas disciplinas de Desenho Técnico Básico, Geometria Descritiva, Desenho Arquitetônico e Desenho Auxiliado por Computador. Os programas desse conjunto de disciplinas apresentam conteúdos de desenho geométrico e CAD 2D, além de noções básicas de projeto arquitetônico ${ }^{2}$. No entanto, a partir de uma análise dos programas do núcleo de disciplinas profissionalizantes e específicas do curso, não se percebe que tal aprendizado de competências básicas, prescritas por French e Vierck, tenha uma conexão explícita com as competências de projeto que deveriam ser desenvolvidas em disciplinas profissionalizantes e específicas do curso. De fato, não é possível encontrar no currículo atual do curso de Engenharia Civil da UFJF disciplinas ou atividades que desenvolvam o projeto de Engenharia Civil na sua plenitude e diversidade.

Neste sentido, pelo seu caráter integrador, na opinião dos autores deste trabalho, o BIM tem o potencial de favorecer o aprendizado das competências do Projeto de Engenharia, pois facilita a integração disciplinar. É possível ainda afirmar que o BIM faz sentido somente num contexto de projeto, visto que permite a integração de todas as facetas vistas disciplinarmente no curso, tanto na perspectiva projetual criativa quanto na de Engenharia Simultânea.

Considerando as ferramentas de Expressão Gráfica como a base da competência projetual, num contexto de BIM elas podem ser reorientadas para o desenvolvimento da competência de Modelagem, que é a essência do Projeto, em vez de manter seu foco apenas na representação geométrica e na habilidade de desenvolvimento de desenhos - sejam eles à mão livre, com instrumentos manuais ou, inclusive, com computadores.

Em consequência, se percebe que a introdução do BIM no currículo do curso de Engenharia Civil é uma iniciativa complexa que exigirá uma reformulação profunda do próprio currículo e, fundamentalmente, uma mudança de visão quanto ao perfil projetual do Engenheiro Civil. No entanto, considerando que mudanças curriculares exigem, de modo geral, acordos amplos que nem sempre são fáceis de serem alcançados, é possível pensar como possibilidade interessante a introdução do BIM através do espaço da Expressão Gráfica.

Considerando que não há prescrição quanto ao uso de instrumentos específicos para a representação gráfica através do Desenho Técnico, é possível e viável a substituição de todos os instrumentos tradicionais - i.e., réguas, esquadros, compassos, etc. - por

\footnotetext{
${ }^{2} \mathrm{O}$ objetivo da disciplina de Projeto Arquitetônico do currículo da UFJF envolve a elaboração apenas de um projeto arquitetônico básico de uma edificação de porte médio.
} 
programas de computador, sem prejuízo para os conteúdos programáticos das disciplinas, deixando o lápis apenas para o esboço à mão livre.

A experiência tem mostrado que o tempo utilizado para o aprendizado de ferramentas de software para desenho é sensivelmente menor que o aprendizado do uso de ferramentas tradicionais. Nessa ótica, o tempo remanescente pode ser dedicado ao aprimoramento da Expressão Gráfica através do desenho à mão livre.

Este deslocamento de foco desde a representação gráfica através de linhas (o ato de "desenhar", próprio do Desenho Técnico com instrumentação tradicional) para a representação de objetos em formato digital, ganha - literalmente - uma nova dimensão, pois programas de computador são capazes de representar objetos com uma riqueza de detalhes e informações muito além daquela obtida a partir de simples desenhos no papel. $E$, em tendo uma representação computacional mais rica, é possível operar em cima dessas novas representações que não apenas abrangem a Expressão Gráfica, mas, também, o conjunto de propriedades de interesse em termos de projeto de engenharia.

O BIM constitui um arcabouço conceitual e ferramental cujo potencial de transformação das práticas de projetar no setor da AEC vem se abrindo rapidamente. A visão atual do BIM é comumente limitada às ferramentas básicas de software para modelagem $3 D$, as quais, embora já mostrem grande potencial de inovação em relação com as ferramentas CAD, são apenas parte do universo do BIM - a ponta visível do iceberg. Não se trata apenas de substituir um programa de CAD 2D por outro BIM 3D. O tema é ver como a riqueza de um modelo BIM faz com que as relações entre os stakeholders mudem, promovendo uma dimensão pouco habitual no contexto da formação dos engenheiros civis na UFJF: a colaboração. Desse modo, além de propiciar o aprendizado de softwares para modelagem 3D, é necessário explorar a integração das disciplinas de projeto (Engenharia Simultânea) através de diferentes esquemas de colaboração.

Diferentemente do CAD, o BIM promove uma aproximação ao pensamento projetual, fazendo um deslocamento da relação cognitiva com o objeto a ser projetado passando da representação tradicional (nas suas mais variadas formas) para a modelagem, numa síntese que facilita o pensar de maneira simultânea os diferentes aspectos do projeto. Portanto, muito mais do que um novo modelo de representação de informações, o BIM exige novas competências para lidar com a complexidade. O simples fato de integrar informações gráficas com informações relevantes ao ciclo de vida da obra exige a derrubada do pensamento disciplinar, estimulando os futuros profissionais a desenvolver habilidades para lidar, minimamente com: a simultaneidade das diferentes disciplinas do projeto, as condições materiais e de produção do projeto e, finalmente, as formas de gestão e negociação dos conflitos entre as diversas abordagens disciplinares do projeto.

\section{A EXPERIÊNCIA DA UFJF NO ENSINO/APRENDIZADO DO BIM}

A formação em BIM deve ter como objetivo a aquisição e desenvolvimento de competências que permitam ao aluno ter uma visão holística do projeto na Engenharia Civil como um campo de realização de obras sob este novo paradigma (BARISON, 2015).

Nesse intuito, no curso de Engenharia Civil da UFJF, o conceito do BIM vem sendo introduzido desde o segundo semestre de 2012, através da disciplina eletiva "Tópicos Especiais em Gerenciamento de Projetos II", com dois créditos e ementa aberta, em torno de tópicos tais como: conceituação do BIM, interoperabilidade, modelos de produto e uso de ferramentas BIM.

O objetivo da disciplina é conduzir um processo de ensino/aprendizado visando à conceituação do BIM. Para alcançar este objetivo, a disciplina contempla, no seu início, uma apresentação, através de aula expositiva, dos aspectos básicos do trabalho a ser 
desenvolvido ao longo do semestre. A partir daí, os alunos se organizam em equipes de três ou quatro membros, a fim de trabalhar ao longo do semestre, perfazendo um caminho com duas vias. A primeira delas consiste num conjunto de discussões em torno de conceitos relacionados com o universo do BIM, a partir de leituras selecionadas. A segunda via consiste num exercício de modelagem 3D e 4D no laboratório de Inovação Tecnológica do Departamento de Construção Civil, inaugurado no primeiro semestre de 2013. Para o trabalho prático são utilizadas versões educacionais de softwares de mercado, entre as quais Autodesk Revit e Graphisoft Archicad, para modelagem geométrica, e Autodesk Navisworks, para modelagem 4D.

O trabalho prático fornece um espaço para a integração de conceitos relacionados com a modelagem e a Expressão Gráfica, que no ferramental BIM ganham uma nova dimensão, e com conceitos relacionados com outras disciplinas do curso. A disciplina eletiva de Desenho Auxiliado por Computador, originalmente focada na visão $C A D$, vem sendo gradualmente adaptada para incorporar ferramentas de modelagem 3D em software BIM.

No âmbito da formação em Expressão Gráfica, estão sendo realizadas algumas mudanças na disciplina de Desenho Técnico Básico, as quais envolvem a substituição gradual do ferramental tradicional - lápis, régua e compasso - por ferramentas de software CAD numa primeira etapa.

Numa primeira aproximação, percebe-se como problema imediato que o trabalho prático sob o novo enfoque envolve como forte restrição o número de equipamentos disponíveis no laboratório. No entanto, considerando a provisão de recursos para o autoaprendizado, atualmente em desenvolvimento, prevê-se que este problema pode ser equacionado através do trabalho autônomo em laboratório, em horários diferenciados, num esquema flexível, ou ainda em casa. Para este fim, será testada inicialmente uma proposta que contempla atividades numa proporção em torno de $80 \%$ presenciais e $20 \%$ em formato flexível.

Nesta abordagem de trabalho ubíquo, há a contribuição fundamental das ferramentas em rede, as quais propiciam uma nova forma de interação distribuída e assíncrona, com o uso de Recursos Educacionais Abertos, os quais propiciam o autoaprendizado. $\mathrm{Na}$ atualidade está sendo produzido material didático para apoio ao autoaprendizado, tendo como base uma série de tutoriais em vídeo orientados ao conjunto de disciplinas relacionadas com o BIM (Desenho Técnico, Desenho Auxiliado por Computador e Tópicos Especiais em Gerenciamento de Projetos II).

$\mathrm{Na}$ configuração atual da proposta em execução, os alunos que optam por cursar as disciplinas eletivas do curso relacionadas com o BIM alcançam um nível de proficiência básico, de acordo com a definição de BARISON (2015). Este nível envolve a definição da geometria de pequenas edificações, contemplando alguns elementos básicos de MEP (Mechanical, Electrical \& Plumbing; ou seja, elementos básicos relacionados com o projeto de sistemas mecânicos, elétricos e de tubulações) e modelagem 4D (a dimensão "tempo"). Alunos que desenvolvem trabalhos posteriores e com foco específico conseguem alcançar um nível intermediário, como é o caso daqueles que desenvolvem Trabalhos de Conclusão de Curso (TCC) sobre o tema.

Os autores deste trabalho esperam que as intervenções em curso no âmbito das disciplinas de Expressão Gráfica relatadas acima abram caminhos para que os níveis de proficiência preconizados por BARISON (2015) possam ser alcançados em etapas anteriores, de modo que exista a opção para que todos alunos interessados no tema possam egressar do curso com um nível de proficiência entre intermediário e avançado. 


\section{RESULTADOS E PERSPECTIVAS}

As iniciativas em torno da introdução do BIM no curso de Engenharia Civil da UFJF têm trazido alguns resultados que - embora modestos - mostram-se promissores. O conceito de BIM começa a ganhar visibilidade e atrai o interesse de alunos não apenas para a disciplina eletiva de BIM, mas para as disciplinas do conjunto vinculado à área de Tecnologia e Gestão de Projetos. $\mathrm{Na}$ atualidade, 20 alunos participam em projetos conduzidos por professores da área, o qual contribui para o estabelecimento de uma massa crítica no curso.

Até o presente momento já foram desenvolvidos três TCC e outros dois encontram-se em andamento, com previsão para serem defendidos até o final do segundo semestre letivo de 2015. Um dos TCC já apresentados foi desenvolvido em parceria com a área de Estruturas, o que inaugura uma nova etapa, que contempla o projeto integrado entre as diferentes disciplinas (LIRA, 2014).

A experiência adquirida desde o início dos trabalhos na área de BIM vem consolidando uma base conceitual sólida, a qual permite a formulação de novos desafios, ao tempo em que fornece os subsídios necessários para começar a definir o conjunto de competências a serem desenvolvidas na formação de engenheiros proficientes em BIM (BARISON, 2015).

$\mathrm{Na}$ atualidade está sendo definido um projeto macro, onde irão participar alunos com diferentes perfis e interesses disciplinares, para os quais professores das áreas correspondentes (Estruturas, Elétrica, Hidráulica e Saneamento) participarão como colaboradores na orientação dos alunos participantes na iniciativa. O objetivo do projeto é por um lado - a compilação de experiência em torno da colaboração em projeto e - por outro - o aprendizado no uso estudo de ferramentas de software para desenvolvimento de projetos em BIM.

Está sendo feita também uma análise do atual currículo do curso para levantar as necessidades de ajuste na sua estrutura, a serem propostas ao colegiado do curso, tendo em vista a importância do aprendizado do BIM.

\section{CONSIDERAÇÕES FINAIS}

Tendo em vista a importância do BIM como um instrumento facilitador tanto de uma visão sistêmica quanto de uma visão projetual na engenharia civil, seu ensino/aprendizado constitui um desafio fundamental para o currículo do curso de Engenharia Civil da UFJF. Nesse sentido, os resultados alcançados até o momento se mostram promissores, uma vez que fazem com que o conceito do BIM venha ganhando a devida visibilidade no âmbito acadêmico.

Embora duas horas por semana numa disciplina eletiva possam parecer pouco (e de fato, são...!), o ganho fundamental é a abertura do horizonte para alunos que começam o curso aprendendo a "projetar" com régua, esquadros e compasso, nas disciplinas de Desenho Técnico e ganham uma visão mais "moderna" do conceito de "projeto" através do aprendizado do Desenho Auxiliado por Computador.

A redefinição do espaço da Expressão Gráfica através da inclusão de novas abordagens e conteúdo constitui um passo interessante, pois consegue o objetivo fundamental de superar o uso de instrumentos tradicionais em prol de novas ferramentas de software, incorporando conceitos de Projeto e trabalho colaborativo.

Porém, estas iniciativas serão ineficazes sem uma profunda reforma curricular do curso, no sentido de atender - por um lado - não apenas as expectativas dos alunos que clamam por um currículo atualizado, mas também as de um mercado que começa a enxergar o potencial do BIM como um caminho para resolver os tradicionais problemas de qualidade $\mathrm{e}$ 
produtividade no setor da AEC.

Não se trata apenas de tornar uma disciplina eletiva de BIM em disciplina obrigatória, nem criar um conjunto de disciplinas em torno do conceito de BIM, pois, mais do que isso, o BIM é um meio pelo qual as diferentes disciplinas do projeto podem se comunicar, o que desloca a discussão para o aspecto da colaboração.

É necessária a introdução do BIM em todas as áreas do currículo do curso de Engenharia Civil, destacando a colaboração como o elemento essencial desta nova visão paradigmática em termos de níveis de proficiência, de acordo com a maturidade do estudante de engenharia (introdutório, intermediário e avançado) (BARISON, 2015).

Há uma série de obstáculos a serem vencidos na instituição, os quais têm a ver, principalmente, com a falta de uma visão crítica e renovada do perfil do Engenheiro Civil, visão esta que se torna necessária em face da nova legislação, que muda os arranjos de competências e atribuições no espaço contínuo entre as profissões do setor da AEC.

\section{REFERÊNCIAS}

AGUILAR, M. \& AZEVEDO, W. Formação em Engenharia Civil: Desafios para o Currículo na UFJF, COBENGE 2014 - Engenharia: Múltiplos Saberes e Atuações, Juiz de Fora, 16 a 19 de setembro de 2014. Disponível em <www.abenge.org.br/cobenge-2014/Artigos/129281.pdf>. Acesso em 10 mai. 2015.

BARISON, M.B. Introdução de modelagem da informação da construção (BIM) no currículo: uma contribuição para a formação do projetista, 2015. 387 p. Tese de Doutorado (Pós-Graduação em Engenharia de Construção Civil). Escola Politécnica, Universidade de São Paulo. São Paulo.

CAU, 1013. Resolução N 51, de 12 de julho de 2013 do Conselho de Arquitetura e Urbanismo do Brasil. Disponível em <www.caubr.gov.br/wp-content/uploads/2012/07/res51-2013atrib-privativas20rpo-1.pdf>. Acesso em 10 mai. 2015.

CNE, 2002. Resolução 11/2002. Diário Oficial da União, Brasília, 9 de abril de 2002. Seção 1, p. 32. Disponível em <portal.mec.gov.br/cne/arquivos/pdf/CES112002.pdf>. Acesso em 10 mai. 2015.

CONFEA, 2013. Resolução $N^{\circ} 1.048$ de 14 de agosto de 2013. Disponível em <normativos.confea.org.br/downloads/1048-13.pdf>. Acesso em 10 mai. 2015.

EASTMAN, C. et AI. BIM Handbook: A Guide to Building Information Modeling for Owners, Managers, Designers, Engineers, and Contractors (Second Edition). New Jersey: John Wiley \& Sons, 2011.

FABRICIO, M.M., Projeto Simultâneo na Construção de Edifícios. 2002. 329p. Tese de Doutorado em Engenharia. Escola Politécnica, Universidade de São Paulo. São Paulo.

FRENCH, T.E., \& VIERCK, C.J. Desenho Técnico e Tecnologia Gráfica. $8^{a}$ Ed. Atualizada, revisada e ampliada. São Paulo: Globo, 2005.

KALE, S. \& ARDITI, D. Diffusion of Computer Aided Design Technology in Architectural Design Practice. Journal of Construction Engineering and Management (ASCE), v. 131, p. 1135-1141, 2005.

LANA, M. \& ANDERY, P. Dificuldades e estratégias para a sustentação dos Programas de garantia da qualidade na Construção Civil Brasileira. In Anais do II SIMPOSIO IBEROAMERICANO SOBRE CALIDAD Y COMPETITIVIDAD EN LAS CONSTRUCCIONES. Habana, Cuba: La Comisión Técnica de Calidad de la Unión Nacional de Arquitectos e Ingenieros de la Construcción, 2002. 
LIRA, F. A verificação de interferências e a Compatibilização de Projetos segundo a metodologia BIM com ênfase no Projeto Estrutural. 2014. 40 f. Trabalho de Conclusão de Curso Faculdade de Engenharia, Universidade de Juiz de Fora, Juiz de Fora, 2014.

SACKS, R., DAVE, B., KOSKELA, L. \& OWEN, R. Analysis Framework For The Interaction Between Lean Construction and Building Information Modeling, Proceedings 17th Annual International Group for Lean Construction Conference, Taiwan (2009).

SANTOS, A. Até o fim da década, BIM estará em todos os projetos. Massa Cinzenta, abr. 2014. Seção Inovação. Disponível em: <www.cimentoitambe.com.br/ate-o-fim-da-decada-bim-estara-emtodos-os-projetos>. Acesso em 10 mai. 2015. 